\title{
Effect of Diode Laser on Gingival Crevicular Fluid Stromal Derived Factor - 1 Alpha Level in Chronic Periodontitis Patients- A Randomized Clinical Trial
}

\author{
Rakesh M. P, Krishna Kripal, Deepthi. R, Sandeep S Prabhu, and Shanmugapriya.P.A
}

\begin{abstract}
Background: SDF-1a may be involved in the immune defense pathway activated during periodontal disease. Upon development of disease, SDF-1 $\alpha$ levels increase and may recruit host defensive cells into sites of inflammation. This suggests that SDF-1 $\alpha$ may be a useful biomarker for the identification of periodontal disease progression. Previous studies suggested that diode laser using as an adjunct to SRP in clinical and biochemical benefits.

Aims and objectives: The aim of the present study was to assess the effect of diode laser on gingival crevicular fluid stromal derived factor -1 alpha (SDF-1a) level in chronic generalized periodontitis patients.

Materials and methods: A total of 30 patients were divided in two groups based on inclusion and exclusion criteria as follows: Group 1: 15 chronic generalized periodontitis patients who received treatment with scaling and root planing. Group 2: 15 chronic generalized periodontitis patients who received treatment with scaling and root planing and diode laser. Each GCF samples were collected at baseline, 15 days and 21 days after treatment. Clinical parameters like gingival index, probing pocket depth and clinical attachment level were recorded and GCF samples also collected.
\end{abstract}

Results: All the clinical parameters (GI, PPD, CAL) and the concentration of SDF-1 $\alpha$ level in GCF were found to be significantly reduced in the group 2 compared to group 1 after 21 days. The mean values of GI, PPD, CAL parameters at different time intervals was found statistically significant in both the groups $(\mathbf{p}<0.001)$.

Conclusion: Within the limitations of the present study, we conclude that diode laser used as an adjunct to SRP provides greater improvement in clinical and biochemical benefits over conventional mechanical treatment during medium term of observation.

Index Terms - Chronic Generalised Periodontitis; Diode laser; Gingival crevicular fluid; SDF-1 $\alpha$.

\section{INTRODUCTION}

Periodontitis is defined as "an inflammatory disease of the supporting tissues of the teeth caused by specific microorganisms or groups of specific microorganisms, resulting in progressive destruction of the periodontal ligament and alveolar bone with pocket formation, recession or both"[1]

Rakesh M. P. , Rakesh Dental Clinic, Bellary, India.

Krishna Kripal, Department of Periodontology, Rajarajeswari Dental College and Hospital, Bangalore, India.

(email: kripalkrishna@yahoo.com)

Deepthi. R, Department of Periodontology, Rajarajeswari Dental College and Hospital, Bangalore, India.

(email: deepthir588@gmail.com)

Sandeep. S. Prabhu, Department of Periodontology, Al-Badar Dental College and Hospital, Gulbarga, India.

Shanmugapriya. P. , Department of Periodontology, Rajarajeswari Dental College and Hospital, Bangalore, India.
Periodontal diseases are among the most prevalent infections in humans; they are characterized by the classic hallmarks of the inflammatory response, including erythema and edema. Late sequelae of periodontal diseases include the loss of alveolar bone, periodontal ligament attachment and ultimately teeth. Therefore, earlier detection and treatment would lead to improved outcomes for patients [2].

Chemokines are a group of small molecular weight proteins characterized by their ability to induce directional movement of a variety of cell types. Stromal derived factor1 (SDF-1 $\alpha$ and $\beta$ or CXC chemokine ligand 12 [CXCL12]) is a potent chemoattractant for hematopoietic cells, including neutrophils. This factor belongs to the $\mathrm{C}-\mathrm{X}-\mathrm{C}$ chemokine family, which was originally isolated from a murine bone marrow stromal cell line. SDF-1 $\alpha$ is selectively expressed by endothelial cells in certain tissues, perhaps in response to specific signals or tissue damage. This may provide a mechanism to localize hematopoietic cells to specific tissue compartments [3].

A recent study revealed that GCF from patients with chronic periodontal diseases has significantly higher levels of SDF- $1 \alpha$ than subjects who are clinically healthy. SDF-1 $\alpha$ may be involved in the immune defense pathway activated during periodontal disease. Upon development of disease, SDF-1 $\alpha$ levels increase and may recruit host defensive cells into sites of inflammation. This suggests that SDF- $1 \alpha$ may be a useful biomarker for the identification of periodontal disease progression [3].

This suggests that SDF-1 $\alpha$ is selectively expressed by endothelial cell in certain tissues, perhaps in response to specific signals or tissue damage. This may provide a mechanism to localize hematopoietic cells to specific tissue compartments. Thus SDF- $1 \alpha$ serves as a biomarker for the risk of periodontal disease progression and is expressed in periodontal lesions and it is correspondingly released in GCF [3].

Based on the involvement of SDF-1 $\alpha$ in hemopoietic cell homing, we hypothesized that the epithelial lining of the gingival sulcus or endothelial cells may secrete the chemokine to recruit mononuclear cells to inflammatory sites. In in vitro studies, we noted that SDF- $1 \alpha$ recruited neutrophils, and in preclinical animal models, SDF-1 $\alpha$ was expressed in the gingival and sulcular epithelium. GCF samples were collected from clinically healthy subjects and from subjects with chronic periodontal disease [3]

Based on the protein levels, GCF from patients with periodontal disease has significantly higher levels of SDF$1 \alpha$ than subjects without periodontal disease. There was also a decrease in SDF-1 $\alpha$ level collected from sites after successful treatment with local mechanical therapy 
measures (scaling and root planing). These data suggest that SDF-1 $\alpha$ may represent a chemoattractant for host defense cells and may serve as a biomarker in GCF for periodontal diseases [3].

Studies have shown that the levels of cytokines reduced significantly when diode lasers were used for the treatment of chronic periodontitis patients [4]

According to our knowledge, there is limited data available regarding the effect of diode laser on SDF- $1 \alpha$ levels whose expressions are modified by the proinflammatory cytokines. Thus the aim of present study was to assess the effect of diode laser on SDF-1 $\alpha$ levels concentration in GCF samples collected from chronic periodontitis patients and also to compare the levels of SDF$1 \alpha$ in GCF samples collected from chronic periodontitis patients treated with scaling and root planing, scaling and root planing and diode laser.

\section{MATERIALS AND METHODS}

\section{A. Patients}

Patients who visited the Department of Periodontology, Rajarajeswari Dental College and Hospital, Bangalore were recruited for the study.

Inclusion criteria were:(1) Patients having minimum of 20 natural teeth; (2) Sites with a probing depth $=5 \mathrm{~mm}$; (3) Sites with clinical attachment loss $=3 \mathrm{~mm}$; (4) Radiographic evidence of alveolar bone loss. Exclusion criteria were:(1) Patients with history of systemic diseases affecting the periodontium; (2) Smokers; (3) Patients on any medication taken within the last 6 months which may alter the periodontal status; (4) Pregnant and lactating mothers; (5) Patients who have undergone periodontal treatment within a period of 1 year.

The study protocol was approved by the Research Ethics Committee of Rajarajeswari Dental college and hospital. All patients were informed about the study and gave written informed consent to participate.

All the subjects underwent a full mouth periodontal probing and charting and were screened for suitability. A proforma was designed for the present study so as to have a systematic and methodical recording of all the observations and information. The relevant data were recorded in the proforma. Chronic periodontitis patients were diagnosed based on criteria discussed at the 1999 International workshop of periodontology.

\section{B. Clinical parameters}

All baseline and follow up, intrasurgical measurements were carried out by the same examiner.

Measurements were made using a graduated William's periodontal probe and were rounded off to the nearest millimeter

Gingival index (Loe H \& Silness P, 1963): Gingival index (GI) was assessed using a mouth mirror and probe. The teeth and gingiva were dried lightly with cotton rolls. The tissues surrounding each tooth were divided into 4 gingival scoring units: distal-facial papilla, facial margin, mesial-facial papilla and the entire lingual gingival margin. Each of the four gingival units was assessed.

Probing Pocket Depth (PPD): The graduated William's periodontal probe was inserted parallel to the long axis of the tooth to measure the pocket depth at 3 buccal (mesiobuccal, midbuccal and distobuccal) and 3 lingual (mesiolingual, midlingual and distolingual) sites for all maxillary and mandibular teeth. The pocket depth was evaluated by determining the distance between crest of the gingival margin to the base of the pocket. Mean pocket depth for a subject was calculated by adding measured pocket depth around all the teeth and divided by number of teeth examined.

Clinical attachment level (CAL): CAL was measured as the distance from the cemento-enamel junction (CEJ) to the base of the gingival sulcus using the periodontal probe. Mean CAL for a subject was calculated by adding measured pocket depth around all the teeth and divided by number of teeth examined.

GI, PPD and CAL were recorded at baseline before any non-surgical periodontal therapy started and also 15 and 21 days after therapy.

\section{SAMPLE COLLECTION}

All the subjects who were screened for suitability were included in the study after obtaining their consent. GCF of approximately $3 \mu \mathrm{l}$ was collected from all the groups by extracrevicular method and was collected using a graduated micro capillary pipette. After GCF collection, the micro capillary pipettes were wrapped in a tin foil and placed in cryovial, sealed with parafilm, and stored at $-70^{\circ} \mathrm{C}$ until analysis. The GCF samples were pipetted using a blower and the entire volume of collected GCF was transferred directly to the prepared microplate wells.

\section{BIOCHEMICAL ANALYSIS}

Quantitative analysis of SDF- $1 \alpha$ Levels in the GCF samples was done using a RayBio ${ }^{\circledR}$ Human SDF-1a ELISA Kit.

\section{A. Principle of the assay:}

The SDF-1 $\alpha$ ELISA (Enzyme-Linked Immunosorbent Assay) kit is an in vitro enzyme-linked immunosorbent assay for the quantitative measurement of human SDF-1 $\alpha$ in plasma, cell culture supernatants and urine. This assay employs an antibody specific for human SDF-1 $\alpha$ coated on a 96-well plate. Standards and samples were pipetted into the wells and SDF-1 $\alpha$ present in a sample was bound to the wells by the immobilized antibody. The wells were washed and biotinylated anti-human SDF- $1 \alpha$ antibody was added. After washing away unbound biotinylated antibody, HRPconjugated streptavidin was pipetted to the wells. The wells were again washed, a TMB substrate solution was added to the wells and colour developed in proportion to the amount of SDF-1 $\alpha$ bound. The Stop Solution changes the colour from blue to yellow, and the intensity of the colour was measured at $450 \mathrm{~nm}$.

\section{B. Additional material required:}

1. Microplate reader capable of measuring absorbance at $450 \mathrm{~nm}$.

2. Precision pipettes to deliver $2 \mu \mathrm{l}$ to $1 \mathrm{ml}$ volumes.

3. Adjustable 1-25 $\mathrm{ml}$ pipettes for reagent preparation.

4. $100 \mathrm{ml}$ and 1 liter graduated cylinders.

5. Absorbent paper.

6. Distilled or deionized water. 
7. Log-log graph paper or computer and software for ELISA data analysis.

8. Tubes to prepare standard or sample dilutions.

\section{Reagent preparation}

1. All reagents and samples were brought to room temperature $\left(18-25^{\circ} \mathrm{C}\right)$ before use.

2. Sample preparation: Assay Diluent A (Item D) was used for dilution of plasma samples.

1x Assay Diluent B (Item E) was used for dilution of culture supernatants and urine.

Plasma: Plasma was collected using heparin, EDTA or citrate as an anticoagulant. Centrifuge for 15 minutes at $1000 \times \mathrm{g}$ within 30 minutes of collection. An additional centrifugation step of the separated plasma at $10,000 \mathrm{x}$ for 10 minutes at $4^{\circ} \mathrm{C}$ was done for complete platelet removal (to measure circulating levels of SDF-1 alpha, platelet- free plasma should be collected).

3. Assay Diluent B was diluted 5-fold with deionized or distilled water.

4. Preparation of standard: vial of Item $C$ was spun and 400 $\mu 1$ Assay Diluent A (for plasma samples) or $1 \mathrm{x}$ Assay Diluent B (for cell culture medium and urine) was added into Item $\mathrm{C}$ vial to prepare a $17 \mathrm{ng} / \mathrm{ml}$ standard. The powder was dissolved thoroughly by a gentle mix. $180 \mu \mathrm{l} \mathrm{SDF-1 \alpha}$ standard from the vial of Item $\mathrm{C}$ was added, into a tube with $330 \mu \mathrm{l}$ Assay Diluent A or 1x Assay Diluent B to prepare a $6,000 \mathrm{pg} / \mathrm{ml}$ stock standard solution. Pipette $250 \mu \mathrm{l}$ Assay Diluent A or 1x Assay Diluent B was pipette into each tube. The stock standard solution was used to produce a dilution series (shown below). Each tube was thoroughly mixed before the next transfer and gently vortexed to mix. Assay Diluent A or 1x Assay Diluent B serves as the zero standards $(0 \mathrm{pg} / \mathrm{ml})$.

5. If the Wash Concentrate (20x) (Item B) contained visible crystals, it was warmed to room temperature and mixed gently until dissolved. $20 \mathrm{ml}$ of Wash Buffer Concentrate was diluted into distilled water to yield $400 \mathrm{ml}$ of 1x Wash Buffer.

6. The Detection Antibody vial (Item F) was spun before use. $100 \mu \mathrm{l}$ of $1 \mathrm{x}$ Assay Diluent B was added into the vial to prepare a detection antibody concentrate. Pipetted up and down to mix gently (the concentrate can be stored at $4{ }^{\circ} \mathrm{C}$ for 5 days). The detection antibody concentrate was diluted 80 fold with 1x Assay Diluent B and used in step 4 of Part.

7. The HRP-Streptavidin concentrates vial (Item G) was spun and pipetted up and down to mix gently before use. HRP-Streptavidin concentrate was diluted 200 -fold with $1 x$ Assay Diluent B.

\section{Assay procedure}

1. All reagents and samples were brought to room temperature $\left(18-25^{\circ} \mathrm{C}\right)$ before use. All standards and samples were run at least in duplicate.

2. $100 \mu \mathrm{l}$ of each standard (see Reagent Preparation step 2) and sample were added into appropriate wells. It was covered well and incubated for 2.5 hours at room temperature or overnight at $4^{\circ} \mathrm{C}$ with gentle shaking.

3. The solution was discarded and washed 4 times with $1 x$ Wash Solution. Wash by filling each well with Wash Buffer $(300 \mu \mathrm{l})$ using a multi-channel Pipette or autowasher. Complete removal of liquid at each step is essential to good performance. After the last wash, remaining Wash Buffer was removed by aspirating or decanting, inverted the plate and bloted it against clean paper towels.

4. $100 \mu \mathrm{l}$ of $1 \mathrm{x}$ prepared biotinylated antibody (Reagent Preparation step 6) was added to each well and incubated for 1 hour at room temperature with gentle shaking.

5. The solution was discarded. Repeat the wash as in step 3. 6. $100 \mu \mathrm{l}$ of prepared Streptavidin solution (see Reagent Preparation step 7) was added to each well and incubated for 45 minutes at room temperature with gentle shaking.

7. The solution was discarded. Repeat the wash as in step 3. 8. $100 \mu \mathrm{l}$ of TMB One-Step Substrate Reagent (Item H) was added to each well and incubated for 30 minutes at room temperature in the dark with gentle shaking.

9. Add $50 \mu \mathrm{l}$ of Stop Solution (Item I) to each well. Read at $450 \mathrm{~nm}$ immediately.

\section{STATISTICAL ANALYSIS}

Mean and Standard Deviations (SD) were calculated for all the parameters for all the study groups. The age distribution between Group I and Group II patients was assessed using Student's unpaired t-test.

The mean values of the measured clinical parameters (GI, PPD, CAL) and GCF and SDF-1a levels for all the study groups were assessed by Student's unpaired t-test. C. The pair-wise comparison was done using Student's paired t-test.

Mean GCF and SDF-1 $\alpha$ levels and comparison of the clinical parameters in pre- and post- treatment chronic periodontitis groups were compared using Student's paired t-test and inter group comparison in two groups was done using ANOVA test.

p-value $<0.05$ was considered as statistically significant. The Statistical Package for Social Sciences software (SPSS) version 17.0 was used to perform the data analyses.

\section{RESULTS}

\section{A. Figures and Tables}

The present randomized controlled trail was designed to quantify and compare the levels of SDF-1 $\alpha$ in GCF samples obtained from chronic generalized periodontitis patients before and after treating with scaling and root planing and Diode laser. We also assessed the effect of diode laser on SDF-1 $\alpha$ levels in GCF collected from chronic generalized periodontitis patients using enzyme linked immunosorbent assay

Mean age of group 1 and group 2 was $43.93 \pm 5.65$ and $43.60 \pm 5.48$ respectively as shown in Table 1, Figure 1 . In both the groups, maximum subjects were $41-50$ years (Table 1). 
TABLE I: AGE DISTRIBUTION OF PATIENTS

\begin{tabular}{|l|l|l|c|c|}
\hline \multirow{2}{*}{ Age in years } & \multicolumn{3}{|c|}{ Group 1: SRP } & $\begin{array}{c}\text { Group } \\
\text { SRP+Laser }\end{array}$ \\
\cline { 2 - 5 } & No & \% & No & \% \\
\hline $20-40$ & 5 & 33.3 & 6 & 40.0 \\
\hline $41-50$ & 8 & 53.3 & 7 & 46.7 \\
\hline $51-60$ & 2 & 13.3 & 2 & 13.3 \\
\hline Total & 15 & 100.0 & 0 & 100.0 \\
\hline Mean \pm SD & $43.93 \pm 5.65$ & $43.60 \pm 5.48$ \\
\hline
\end{tabular}

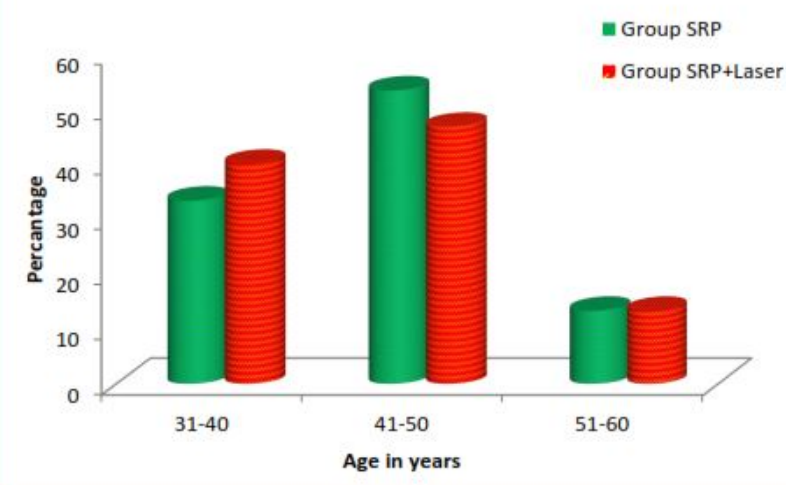

Fig. 1. Mean age distribution at different years in each group.

Gender was almost equally distributed in group 1 and group 2. (53.3\% males and 46.7\% females) (Table 2, Figure 2).

TABLE 2: GENDER DISTRIBUTION OF PATIENTS

\begin{tabular}{|l|l|l|c|c|}
\hline \multirow{2}{*}{ Gender } & \multicolumn{2}{|c|}{ Group 1: SRP } & \multicolumn{2}{c|}{$\begin{array}{c}\text { Group } \\
\text { SRP+Laser }\end{array}$} \\
\cline { 2 - 5 } & No & \% & No & \% \\
\hline Female & 7 & 46.7 & 8 & 53.3 \\
\hline Male & 8 & 53.3 & 7 & 46.7 \\
\hline Total & 15 & 100.0 & 15 & 100.0 \\
\hline
\end{tabular}

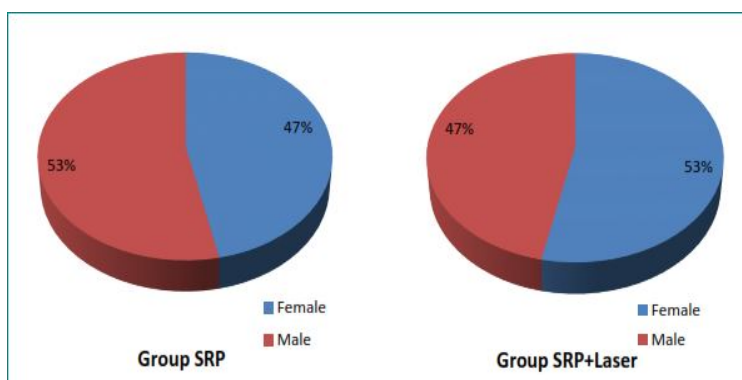

Fig 2: Gender distributition shown in pie chart

We found that the mean gingival index among the two groups was statistically significant after 15 days of SRP and diode laser treatment. $(p<0.009$, Table 3$)$. The mean gingival index at different time intervals, baseline to 15 days, baseline to 21 days and 15 to 21 days was found statistically significant in both the groups $(\mathrm{p}<0.001)$ as shown in Table 4 and Figure 3.

TABLE 3: COMPARATIVE EVALUATION OF GINGIVAL INDEX (GI) IN TWO GROUPS

\begin{tabular}{|l|c|c|c|}
\hline GI & $\begin{array}{c}\text { Group 1: } \\
\text { SRP }\end{array}$ & $\begin{array}{c}\text { Group 2: } \\
\text { SRP+Laser }\end{array}$ & p-value \\
\hline Baseline & $2.40 \pm 0.15$ & $2.42 \pm 0.14$ & 0.702 \\
\hline
\end{tabular}

\begin{tabular}{|cc|c|c|c|}
\hline $\begin{array}{c}\text { After } \\
\text { days }\end{array}$ & 15 & $1.48 \pm 0.12$ & $1.37 \pm 0.10$ & $0.009^{* *}$ \\
\hline $\begin{array}{c}\text { After } \\
\text { days }\end{array}$ & 21 & $1.15 \pm 0.20$ & $1.11 \pm 0.17$ & 0.493 \\
\hline
\end{tabular}

TABLE 4: COMPARATIVE EVALUATION OF GINGIVAL INDEX (GI) AT DIFFERENT INTERVALS OF EACH GROUP GROUP 1: SRP

\begin{tabular}{|c|l|l|}
\hline & Difference & p- value \\
\hline $\begin{array}{c}\text { Baseline to after 15 } \\
\text { days }\end{array}$ & 0.920 & $<0.001^{* *}$ \\
\hline $\begin{array}{c}\text { Baseline to after 21 } \\
\text { days }\end{array}$ & 1.247 & $<0.001^{* *}$ \\
\hline After 15 to 21 days & 0.327 & $<0.001^{* *}$ \\
\hline
\end{tabular}

\begin{tabular}{|l|l|l|}
\hline \multicolumn{2}{|c|}{ GROUP 2: SRP+ Laser } \\
\hline $\begin{array}{c}\text { Baseline to after 15 } \\
\text { days }\end{array}$ & Difference & p-value \\
\hline $\begin{array}{c}\text { Baseline to after 21 } \\
\text { days }\end{array}$ & 1.053 & $<0.001^{* *}$ \\
\hline After 15 to 21 days & 0.260 & $<0.001^{* *}$ \\
\hline
\end{tabular}

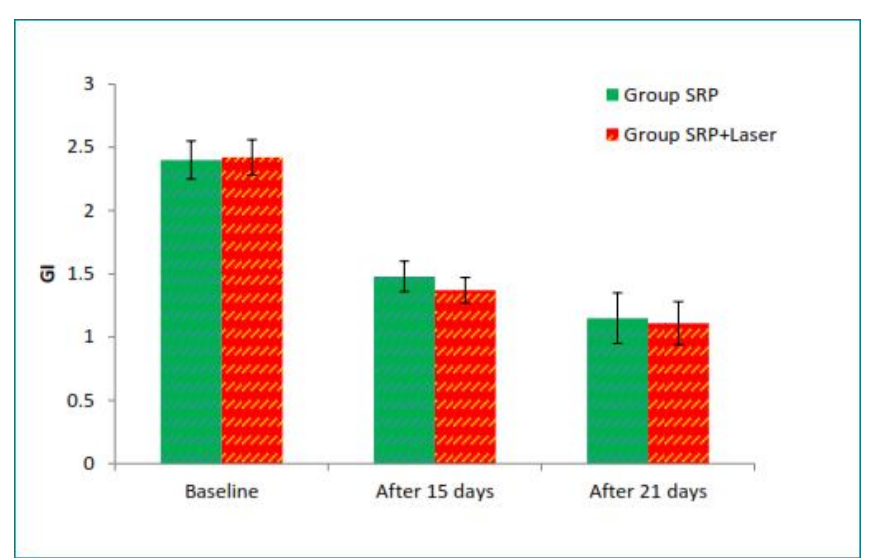

Fig 3: Comparative evaluation of gingival index at different intervals in 2 groups

Similarly, the difference in the mean pocket depth among two groups was not statistically significant $(\mathrm{p}<0.141$, Table 5 ) but the mean PPD at different time intervals was statistically significant in both the groups $(p<0.001)$ as shown in Table 6 and Figure 4.

TABLE 5: COMPARATIVE EVALUATION OF PPD (MM) IN TWO GROUPS STUDIED

\begin{tabular}{|c|c|c|c|}
\hline PPD & $\begin{array}{c}\text { Group 1: } \\
\text { SRP }\end{array}$ & $\begin{array}{c}\text { Group 2: } \\
\text { SRP+Laser }\end{array}$ & p-value \\
\hline Baseline & $6.95 \pm 0.35$ & $6.95 \pm 0.35$ & 0.959 \\
\hline $\begin{array}{c}\text { After 15 } \\
\text { days }\end{array}$ & $6.09 \pm 0.29$ & $6.15 \pm 0.26$ & 0.514 \\
\hline $\begin{array}{c}\text { After 21 } \\
\text { days }\end{array}$ & $5.69 \pm 0.30$ & $5.83 \pm 0.22$ & 0.141 \\
\hline
\end{tabular}

TABLE 6: COMPARATIVE EVALUATION OF PROBING POCKET DEPTH AT DIFFERENT INTERVALS OF EACH GROUP.

GROUP 1: SRP

\begin{tabular}{|c|l|l|}
\hline & Difference & $\mathrm{p}$ - value \\
\hline $\begin{array}{c}\text { Baseline to } \\
\text { after 15 days }\end{array}$ & 0.860 & $<0.001^{* *}$ \\
\hline Baseline to & 1.260 & $<0.001^{* *}$ \\
\hline
\end{tabular}




\begin{tabular}{|l|l|l|}
\hline after 21 days & & \\
\hline $\begin{array}{c}\text { After } 15 \text { to } 21 \\
\text { days }\end{array}$ & 0.400 & $<0.001^{* *}$ \\
\hline
\end{tabular}

\begin{tabular}{|c|c|c|}
\hline \multicolumn{3}{|c|}{ GROUP 2: SRP+ LASER } \\
\hline & Difference & p-value \\
\hline $\begin{array}{cc}\text { Baseline } & \text { to } \\
\text { after 15 days }\end{array}$ & 0.800 & $<0.001^{* *}$ \\
\hline $\begin{array}{cc}\text { Baseline } & \text { to } \\
\text { after 21 days }\end{array}$ & 1.120 & $<0.001 * *$ \\
\hline $\begin{array}{l}\text { After } 15 \text { to } 21 \\
\text { days }\end{array}$ & 0.320 & $<0.001 * *$ \\
\hline
\end{tabular}

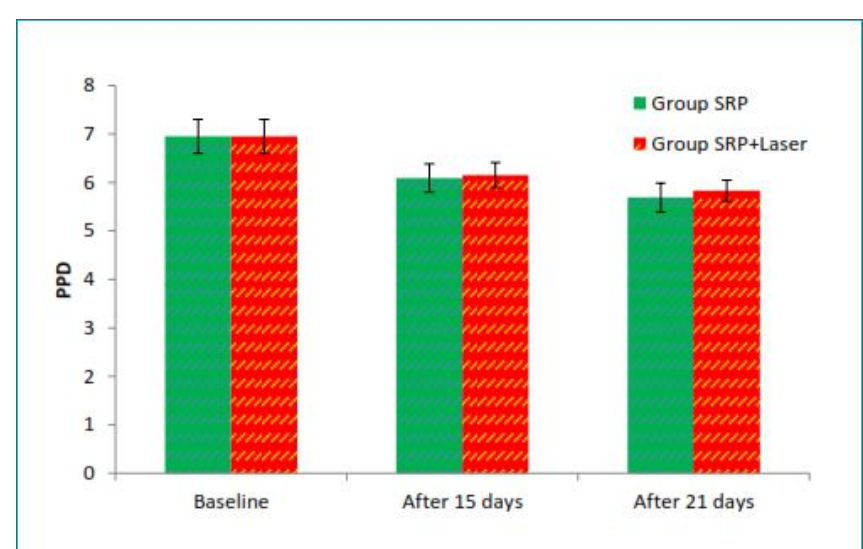

Fig 4: Comparative evaluation of PPD (mm) at different intervals in 2 groups

The difference in the mean CAL in between groups was not significant $(\mathrm{p}=0.362$, Table 7$)$ but the mean CAL at different time intervals was statistically significant in both the groups $(\mathrm{p}<0.001)$ as shown in Table 8 and Figure 5.

TABLE 7: COMPARATIVE EVALUATION OF CAL (mm) IN THE TWO GROUPS STUDIED

\begin{tabular}{|c|c|c|c|}
\hline CAL & $\begin{array}{l}\text { Group 1: } \\
\text { SRP }\end{array}$ & $\begin{array}{cc}\text { Group } & 2: \\
\text { SRP+Laser } & \\
\end{array}$ & p-value \\
\hline Baseline & $7.07 \pm 0.40$ & $7.20 \pm 0.32$ & 0.325 \\
\hline $\begin{array}{ll}\begin{array}{c}\text { After } \\
\text { days }\end{array} & 15 \\
\end{array}$ & $6.80 \pm 0.43$ & $6.85 \pm 0.34$ & 0.712 \\
\hline $\begin{array}{ll}\text { After } & 21 \\
\text { days }\end{array}$ & $6.65 \pm 0.42$ & $6.52 \pm 0.32$ & 0.362 \\
\hline
\end{tabular}

TABLE 8: COMPARATIVE EVALUATION OF CAL (mm) AT DIFFERENT INTERVALS OF EACH GROUP.

\begin{tabular}{|c|l|l|}
\multicolumn{2}{|l}{ GROUP 1: SRP } \\
\hline $\begin{array}{c}\text { Baseline to after 15 } \\
\text { days }\end{array}$ & 0.267 & D-value \\
\hline $\begin{array}{c}\text { Baseline to after 21 } \\
\text { days }\end{array}$ & 0.420 & $<0.001^{* *}$ \\
\hline After 15 to 21 days & 0.153 & $<0.001^{* *}$ \\
\hline
\end{tabular}

\begin{tabular}{|c|c|c|}
\multicolumn{2}{l}{ GROUP 2: SRP+ LASER } \\
\hline $\begin{array}{c}\text { Baseline to after 15 } \\
\text { days }\end{array}$ & Difference & p- value \\
\hline $\begin{array}{c}\text { Baseline to after 21 } \\
\text { days }\end{array}$ & 0.347 & $<0.001^{* *}$ \\
\hline After 15 to 21 days & 0.333 & $<0.001^{* *}$ \\
\hline
\end{tabular}

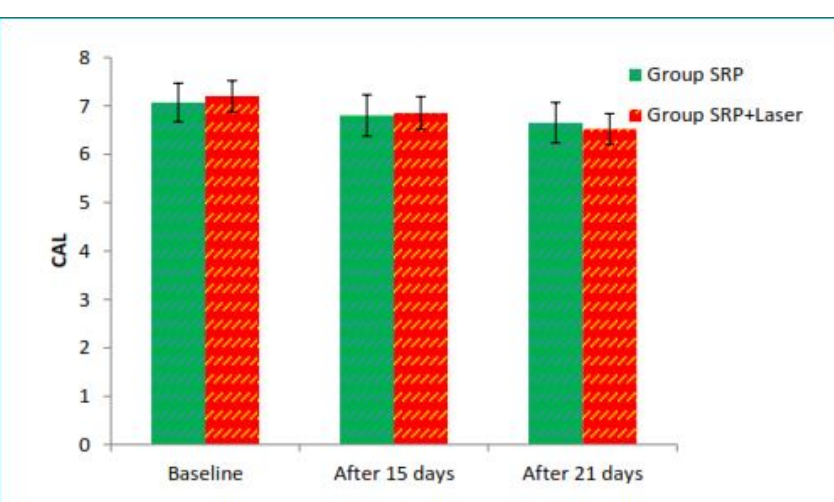

Fig 5: Comparative evaluation of CAL (mm) at different intervals in 2 groups

\section{B. SDF-1 a Level concentration in GCF before and after} ELISA process.

The results of our study indicated that the mean SDF- $1 \alpha$ concentration in GCF was highest in group 1 and group 2 at baseline $(844.07 \pm 362.69 \mathrm{pg} / \mathrm{ml}$ and $854.91 \pm 366.11 \mathrm{pg} / \mathrm{ml})$. There was significant reduction in the SDF-1 $\alpha$ concentration from baseline to 15 and 21 days after SRP and diode laser treatment. The difference in mean SDF- $1 \alpha$ concentration in GCF samples was found statistically significant after 21 days $(\mathrm{p}<0.001$, Table 9$)$ and at different time intervals also. $(\mathrm{p}<0.001$, Table 10, Figure 6)

TABLE 9: SDF-1 $\alpha$ CONCENTRATION VALUE (PG/ML) OF TWO STUDY GROUP

\begin{tabular}{|c|c|c|c|}
\hline $\begin{array}{c}\text { SDF-1 } \alpha \\
\text { concentration } \\
\text { value (pg/ml) }\end{array}$ & Group 1: SRP & $\begin{array}{c}\text { Group 2: } \\
\text { SRP+Laser }\end{array}$ & p-value \\
\hline Baseline & $844.07 \pm 362.69$ & $854.91 \pm 366.11$ & 0.936 \\
\hline After 15 days & $393.97 \pm 126.42$ & $397.16 \pm 78.33$ & 0.934 \\
\hline After 21 days & $307.40 \pm 66.44$ & $263.45 \pm 41.27$ & $0.038^{*}$ \\
\hline
\end{tabular}

TABLE 10: COMPARATIVE EVALUATION OF SDF-1 $\alpha$ LEVEL CONCENTRATION AT DIFFERENT INTERVALS OF EACH GROUP

\begin{tabular}{|c|c|c|}
\hline \multicolumn{3}{|c|}{ GROUP 1: SRP } \\
\hline $\begin{array}{c}\text { Baseline to after } \\
15 \text { days }\end{array}$ & Difference & p- value \\
\hline $\begin{array}{c}\text { Baseline to after } \\
21 \text { days }\end{array}$ & 536.101 & $<0.001^{* *}$ \\
\hline $\begin{array}{c}\text { After 15 to } 21 \\
\text { days }\end{array}$ & 86.569 & $<0.001^{* *}$ \\
\hline
\end{tabular}

\begin{tabular}{|c|c|c|}
\hline \multicolumn{3}{|c|}{ GROUP 2: SRP+ LASER } \\
\hline $\begin{array}{c}\text { Baseline to after } \\
15 \text { days }\end{array}$ & Difference & p- value \\
\hline $\begin{array}{c}\text { Baseline to after } \\
21 \text { days }\end{array}$ & 457.75 & $<0.001^{* *}$ \\
\hline $\begin{array}{c}\text { After } 15 \text { to } 21 \\
\text { days }\end{array}$ & 133.71 & $<0.001^{* *}$ \\
\hline
\end{tabular}




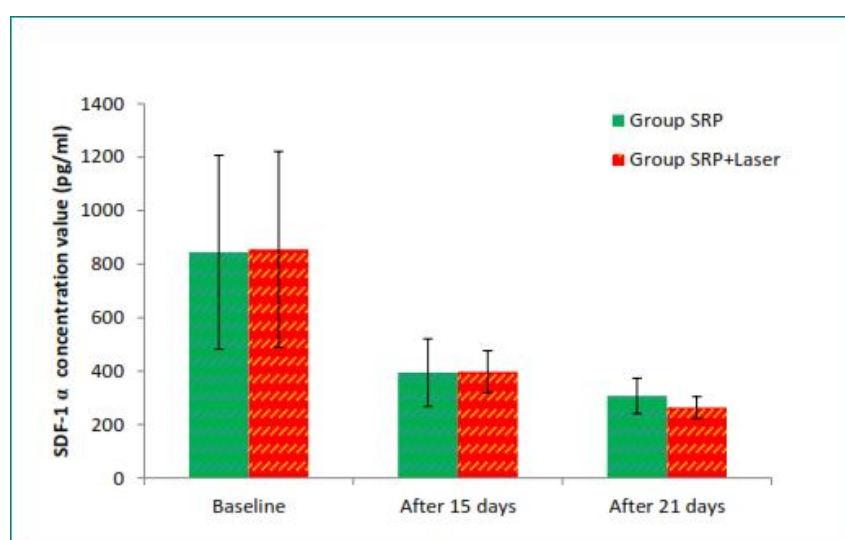

Fig 6: Comparative evaluation of SDF-1 $\alpha$ concentration at different intervals in 2 groups

Preliminary investigations were performed to ensure that the GCF sampling methods were compatible with detecting SDF-1 $\alpha$. SDF-1 $\alpha$ was detected by an ELISA assay using known concentrations of recombinant human SDF-1 $\alpha$ absorbed onto and eluted from the microcapillary pipettes in accordance with the studies conducted by Havens AM et al in 2008 .

This study showed greater reduction in the concentration of SDF-1 $\alpha$ level in GCF as found in group 2 compare to group 1 after 21 days. (Table 9) Because degradation of SDF-1 $\alpha$ plays a significant role in regulating the bioavailability of the chemokine, which is in line with the studies conducted by Havens AM et al in $2008^{3}$

It was found the effect of diode laser as an adjunctive to SRP on Stromal derived factor - 1alpha level showed greater reduction in concentration in chronic generalized periodontitis patients compared to SRP alone treated patients after 21days. All other clinical parameters viz, reduction of gingival score, gain in probing pocket depth and clinical attachment level was statically significant in group 2 as compare to group 1.

We found that in group 1 after SRP there was decrease of $63.20 \%$ in SDF- $1 \alpha$ levels concentration in GCF samples collected from Chronic generalized periodontitis patients after 21 days $(844.07 \pm 362.69 \mathrm{pg} / \mathrm{ml}$ total protein to $307.40 \pm 66.44 \mathrm{pg} / \mathrm{ml}$ total protein).

Similarly, we found that there was $69.20 \%$ greater reduction of SDF-1 $\alpha$ levels concentration following diode laser as an adjunctive to SRP (group 2).

The standard curve with four parameters logistic regression analysis revealed that there was gradual increase in optical density values corresponding to SDF- $1 \alpha$ levels concentration in GCF samples as showed in Figure 7.

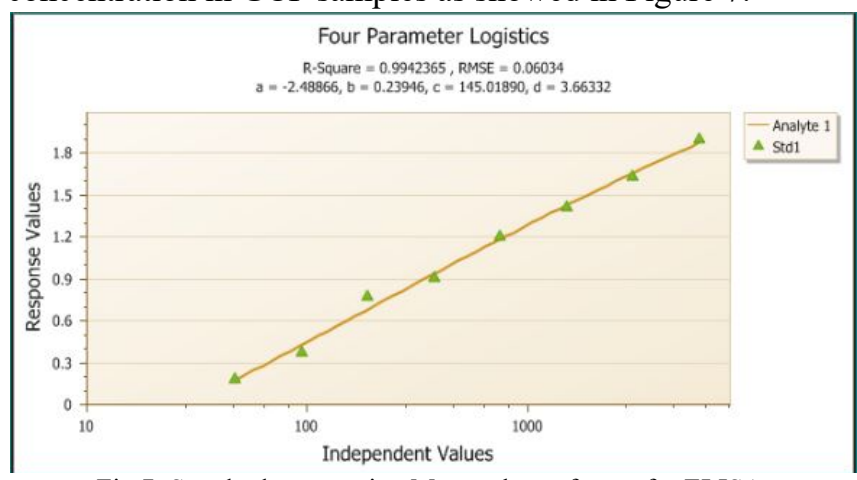

Fig 7: Standard curve using Masterplex software for ELISA

\section{DISCUSSION}

Chronic periodontitis is an inflammatory response to the accumulation of microbial plaque and calculus on the root surface of the tooth; which leads to destruction of the surrounding periodontal tissues 1 . The goal of periodontal therapy is to arrest the inflammatory processes by reducing the number of pathogenic periodontal microorganisms. The success of periodontal therapy depends on the effective removal of supra- and subgingival bacterial biofilms and the smear layer, which contains bacteria, bacterial endotoxins and contaminated root cementum [2], [3].

Removing these pathological substances ensures biological compatibility between the diseased periodontal radicular surface and new connective tissue attachment [3].

Non-surgical periodontal therapy is the primary recommended approach to control periodontal infection is based on the removal of supra- and subgingival calculus and bacterial biofilms using hand instruments and ultrasonic scalers. Although systematic reviews have indicated a similar improvement in clinical parameters following the use of hand and ultrasonic instrumentation, ultrasonic root debridement has been favoured by some researchers because of increased efficiency. Moreover, compared to manual instrumentation, ultrasonic instrumentation requires less time and physical effort. However, complete removal of the bacteria biofilm and their endotoxins in deeper areas of the pockets and furcation sites is often difficult to achieve with both methods [4].

Laser therapy has been proposed as an alternative or adjunctive treatment to conventional periodontal therapy. A variety of lasers have been proposed, including the $\mathrm{CO}$; neodymium- doped: yttrium, aluminum, and garnet (Nd:YAG); diode; and erbium-doped: YAG (Er:YAG) lasers. The bactericidal and detoxifying effects of the diode laser during non-surgical periodontal treatment have been documented.5-9) For patients with periodontitis, the adjunctive use of a diode laser with scaling and root planing (SRP) has shown a superior effect over SRP or the laser alone for certain microbial and clinical parameters [10].

However, when used as an adjunct to SRP, an 805-nm diode laser was shown to have an additive effect in reducing subgingival bacteria in periodontal pockets measuring $=4$ $\mathrm{mm}[10]$.

Diode lasers (810-980 $\mathrm{nm}$ range) emit laser light in the near infra-red spectrum of the electromagnetic radiation which are highly absorbed in haemoglobin and other pigments. One of the main benefits of using diode lasers is the ability to selectively and precisely interact with diseased tissues. Lasers also allow the clinician to reduce the amount of bacteria and other pathogens in the surgical field and in the case of soft-tissue procedures, achieve good haemostasis without sutures [11], [12].

The purported advantages of diode lasers versus conventional surgery include increased coagulation that yields a dry surgical field and better visualization; the ability to negotiate curvatures and folds within tissue contours; tissue surface sterilization and therefore, reduction in bacteraemia; decreased swelling, edema, and scarring; decreased pain; faster healing response; and increased patient acceptance [12], [13]

When laser cutting is in progress, small blood and 
lymphatic vessels are sealed due to the generated heat, thereby reducing or eliminating bleeding and edema. Denatured proteins within tissue and plasma are the source of the layer termed "coagulum", which is formed because of laser action and serves to protect the wound from bacterial or frictional action. Also the diode laser did not produce any deleterious effect on the root surface. Therefore, diode laser surgery can be performed safely in close proximity to dental hard tissue. During SRP procedure, there was no bleeding and postoperatively no pain was experienced by the patient and no swelling or any other signs of infection were noticed, whereas conventional procedures require the administration of antibiotics and analgesics to minimize postoperative infection and pain [5]- [9].

Studies done by Pirnat [14] demonstrated the cutting ability of the soft tissue diode laser with a depth of 2-6mm into the tissues with the sealing of small blood and lymphatic vessels as a result of the heat generated thereby eliminating bleeding and edema.

According to our knowledge, there is limited data available regarding the effect of diode laser on SDF-1 $\alpha$ levels whose expressions are modified by the proinflammatory cytokines. Hence the aim of the present study was to assess the effect of diode laser on gingival crevicular fluid stromal derived factor -1 alpha level in chronic generalized periodontitis patients before and after scaling and root planing.

The present randomized controlled study results indicated that there was statistically significant reduction of SDF- $1 \alpha$ levels using diode laser more an adjunctive to SRP than compared to conventional SRP after 21 days. All the clinical parameters (GI, PPD, CAL) were found to be significantly reduced in the group 2 compared to group 1 . The difference in the mean concentration of SDF-1 $\alpha$ level from baseline to 21 days was statistical significant. (Table 9) The difference in the mean parameters, GI, PPD and CAL at various time intervals like baseline to after 15 days, baseline to after 21 days and after 15 to 21 days was not statistically significant in both the groups except the difference in mean gingival index among the two groups at after 15 days $(p<0.009$, Table 3).

The present study results are in line with previous studies have shown that the levels of cytokines reduced significantly when diode lasers were used for the treatment of chronic periodontitis patients [4].

Havens AM et al., revealed that GCF from patients with chronic periodontal diseases has significantly higher levels of SDF-1 $\alpha$ than subjects who are clinically healthy. SDF-1 $\alpha$ may be involved in the immune defense pathway activated during periodontal disease. Upon development of disease, SDF-1 $\alpha$ levels increase and may recruit host defensive cells into sites of inflammation. This suggests that SDF-1 $\alpha$ may be a useful biomarker for the identification of periodontal disease progression.

In a systematic review, Karlsson et al [15] concluded that a limited number of studies had evaluated the clinical effects of lasers used adjunctively with SRP. Another study results indicated that adjunctive use of a 980-nm diode laser with SRP offers minimal additional benefit in the treatment of chronic periodontitis [10].

Previous studies have reported significant differences of
GCF levels of selected cytokines before and after initial periodontal therapy with or without adjunctive laser treatment.4) GCF is the best source to assess the inflammatory mediators in periodontal disease. The biochemical analysis of GCF offers a non-invasive approach for assessing the host response in individuals with periodontitis. Among many inflammatory and immune mediators identified in the GCF, cytokines have attracted particular attention and are suspected to be involved in both inflammation-related alteration and repair of the periodontal tissues. Conversely, several acute-phase reactants, despite being produced in tissues remote from the infection, may be affected by effective periodontal therapy [4].

Chemokines are a family of chemotactic cytokines that comprise $>50$ related proteins, which are divided into four subfamilies, $\mathrm{C}, \mathrm{CC}, \mathrm{CXC}$, and $\mathrm{CX} 3 \mathrm{C}$, in which $\mathrm{X}$ is any amino acid. Chemokines are functionally vital in cell activation, differentiation, and survival through binding to G-protein-coupled seven transmembrane spanning serpentine receptors. Stromal cell-derived factor-1 (SDF1)/pre-B-cell growth-stimulating factor (CXCL12), a member of the CXC chemokine subfamily, plays important role in survival, growth and migration of different cell types by activation of a G-protein-coupled receptor, CXCR4. SDF-1 acts as a chemoattractant for periosteal PCs, hematopoietic stem cells, and MSCs and supports their survival and proliferation [16].

Stromal cell-derived factor 1 (SDF-1) is a CXC chemokine that attracts hemopoietic progenitor cells lymphocytes and monocytes in vitro and is required for fetal B lymphopoiesis and myelopoeisis in vivo. It is highly conserved between species; human and mouse SDF-1 $\alpha$ are 99\% identical, making SDF-1 the most highly conserved chemokine described to date. Two alternate splice variants of the sdf1 gene give rise to SDF- $1 \alpha$ and SDF-1ß, which are identical, except that SDF-1ß contains an additional four amino acid residues in the carboxyl terminus. There appear to be no differences between SDF-1 $\alpha$ and SDF-1ß in regulated expression or function [17].

Earlier study reported that SDF-1 recruits' human PDLSCs in vitro and SDF-1 may exert its migratory effect through its receptor CXCR4. SDF-1 also promotes cellular viability and proliferation and influences the differentiation of PDLSCs. All these findings indicate that application of SDF-1 holds promise for in situ therapies of periodontal tissue regeneration based on guiding PDLSCs to periodontal defects and encourages additional in vivo studies [16].

Only two studies have reported differences in the expression of certain GCF components: Liu et al.18) reported that the Nd:YAG laser combined with SRP showed a higher reduction of GCF IL-1ß at 6 and 12 weeks after treatment than either laser alone or SRP alone. Dominguez et al.19) monitored the levels of GCF IL-1ß and TNF-a during a period of 8 weeks after SRP alone or SRP plus Er:YAG laser radiation. GCF levels of IL-1ß and TNF-a were higher after SRP alone and slightly lower after the combined procedure. The authors suggested that diode laser treatment may reduce mechanical damage when frequent treatment of persistent pockets and prevent rapid bacterial recolonization.

The positive effects in the decontamination of periodontal 
pockets can be achieved by using diode laser of $1 \mathrm{~W}$. This is attributable to the elimination of bacteria by direct absorption of light. So, this can be minimally invasive as a long-term alternative therapy without mechanical interaction [13].

In 2008, authors suggested that individual periodontal sites, the epithelial lining of the periodontal sulcus or pocket may release higher concentrations of SDF-1 $\alpha$ to attract more neutrophils to amplify the immune response corresponding to the aggressiveness of the disease. Because it is unlikely that SDF-1 $\alpha$ serum levels change in response to local infections, their findings agree with the histologic observations that SDF-1 $\alpha$ provides a biologic explanation for cellular trafficking into the local periodontal infection sites.

Akimoto et al., demonstrated that healing of human gastric ulcers express high levels of VEGF receptors early in ulcer development and SDF- $1 \alpha$ participates in the initial stage of angiogenesis. SDF- $1 \alpha$ receptors are primarily expressed during the later stages of wound healing, which suggests that SDF-1 $\alpha$ may also be involved in vascular maturation and gastric mucosal regeneration during late angiogenesis. Basal levels of SDF-1 $\alpha$ production and secretion into the GCF may maintain the presence of immune surveillance mechanisms in the gingival connective tissues [3].

Previous studies have demonstrated the expression of SDF- $1 \alpha$ in periodontal lesions and corresponding release in the oral fluids (GCF) associated with diseased periodontal sites. Furthermore, the induction of SDF-1 $\alpha$ was noted following the development of periodontitis in a $\mathrm{P}$. gingivalis LPS-mediated model of periodontal disease progression. Thus, these data suggest that SDF-1 $\alpha$ may have a role in the development of periodontal disease. Future studies may in the determination of the role SDF- $1 \alpha$ serves as a biomarker of the risk for periodontal disease progression [3].

Future studies done on larger sample size to assess the various prospective of SDF-1 $1 \alpha$ will enhance or understanding about its role in the pathogenesis of periodontal disease.

\section{CONCLUSION}

In the present study, there was a greater reduction of SDF- $1 \alpha$ concentration in GCF after using diode laser as an adjunct to SRP than SRP alone and slight improvement of clinical parameters (GI, PPD, CAL) after 21 days. Within the limitations, we suggest that diode laser provides improvement in clinical and biochemical benefits over conventional mechanical treatment during medium term of observation

\section{ACKNOWLEDGMENT}

No commercial relationship or conflict of interest with any of the products used in this investigation, and the study is designed by our own initiative. Our study was self-funded by the authors and the institution.

\section{REFERENCES}

[1] Novak MJ. Classification of diseases and conditions affecting the periodontium. In Newman MG, Takei HH, Klokkevold PR, Carranza FA editors; Carranza's Clinical Periodontology, 10th Edition. Philadelphia: W.B. Saunders Co. 2006: 103-104.

[2] Giannobile WV. Host-response therapeutics for periodontal diseases. J Periodontol 2008; 79:1592-1600.

[3] Havens AM, Chiu E, Taba M, Wang J, Shiozawa Y, Jung Y et al. Stromal-derived factor-1alpha (CXCL12) levels increase in periodontal disease. J Periodontol 2008; 79(5):845-53.

[4] Giannopoulou C, Cappuyns I, Cancela J, Cionca N, Mombelli A. Effect of Photodynamic Therapy, Diode Laser, and Deep Scaling on Cytokine and Acute- Phase Protein Levels in Gingival Crevicular Fluid of Residual Periodontal Pockets. J Periodontol 2012; 83:101827.

[5] Bader H I. Use of lasers in periodontics. Dent Clin North Am 2000; 44; 779-791.

[6] Aoki A, Sasaki KM, Watanabe H. Lasers in nonsurgical periodontal therapy. Periodontology 2000, Vol. 36, 2004, 59-97.

[7] Cobb CM. Lasers in Periodontics: A Review of the Literature. J Periodontol 2006; 77: 545-564

[8] Schwarz F, Aoki A, Becker J. A Laser application in non-surgical periodontal therapy: a systematic review. J Clin Periodontol 2008; 35 (8): 29-44.

[9] Karlsson MR, Lofgren CID, Jansson HM. The Effect of Laser Therapy as an Adjunct to Non-Surgical Periodontal Treatment in Subjects with Chronic Periodontitis: A Systematic Review. J Periodontol 2008; 79:2021-2028.

[10] W, Bago I, Aurer A, Roguljic M. Clinical Effectiveness of Diode Laser Therapy as an Adjunct to Non-Surgical Periodontal Treatment: A Randomized Clinical Study. J Periodontal 2012; 10:146-153.

[11] Coluzzi D J. Fundamentals of dental lasers: science and instruments. Dent Clin N Am 48; 2004; 751-770.

[12] Parker S. Laser tissue interaction. Br Dent J 2007; 202; 73-81.

[13] Convissar RA. The biologic rationale for the use of lasers in dentistry. Dent Clin N Am 48; 2004; 771-794

[14] Pirnat S. Versatility of an $810 \mathrm{~nm}$ Diode Laser in Dentistry: An Overview. J Laser Hea Acad 2007; 4:1-9.

[15] Karlsson MR, Lofgren CID, Jansson HM. The Effect of Laser Therapy as an Adjunct to Non-Surgical Periodontal Treatment in Subjects with Chronic Periodontitis: A Systematic Review. J Periodontol 2008; 79:2021-2028.

[16] Du L, Yang P, Ge S. Stromal cell-derived factor-1 significantly induces proliferation, migration, and collagen type I expression in a human periodontal ligament stem cell subpopulation. J Periodontol 2012; 83(3):379-88.

[17] Gupta SK, Pillarisetti K, Lysko PG. Modulation of CXCR4 expression and SDF-1 $\alpha$ functional activity during differentiation of human monocytes and macrophages. J Leukoc Biol 1999; 66: 135-43.

[18] Ghadge SK, Mühlstedt S, Ozcelik C, Bader M. SDF-1a as a therapeutic stem cell homing factor in myocardial infarction. Pharmacol Ther 2011; 129(1):97-108.

[19] Wang K. Overexpression of SDF-1a enhanced migration and engraftment of cardiac stem cells and reduced infarcted size via CXCR4/PI3K pathway. PLoS One 2012; 7(9):439-42.

[20] Katsikanis F, Strakas D, Vouros I. The application of antimicrobial photodynamic therapy (aPDT, $670 \mathrm{~nm})$ and diode laser $(940 \mathrm{~nm})$ as adjunctive approach in the conventional cause-related treatment of chronic periodontal disease: a randomized controlled split-mouth clinical trial. Clin Oral Investig. 2019 Aug 13.

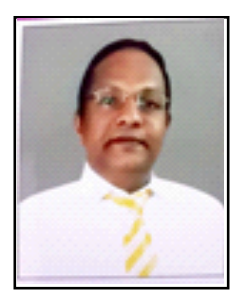

Prof. Dr. Krishna Kripal was born in Bangalore on 01/06/1969. He completed Bachelor of Dental surgery from College of Dental sciences, Mangalore and Masters of Dental Surgery in the Dept. of Periodontology from M R Ambedkar Dental College, Bangalore.

He was previously working as a READER in Hasanamba Dental College, Hassan. Currently he is a PROFESSOR in Rajarajeswari Dental College and Hospital, Bangalore. He has published several articles and books. Fundamentals and applications of laser dentistry; Sapna Ink; 2016, Integrated medicine and Periodontics, Scholars' Press, 2019

Prof. Dr. Kripal is a member of Indian Society of Periodontology and Indian Dental Association. 